\title{
Movement, Wildness and Animal Aesthetics
}

\section{TOM GREAVES}

\section{Philosophy}

University of East Anglia

Norwich, NR4 7TJ, UK

Email:T.Greaves@uea.ac.uk

\begin{abstract}
The key role that animals play in our aesthetic appreciation of the natural world has only gradually been highlighted in discussions in environmental aesthetics. In this paper I make use of the phenomenological notion of 'perceptual sense' as developed by Merleau-Ponty to argue that open-ended expressive-responsive movement is the primary aesthetic ground for our appreciation of animals. It is through their movement that the array of qualities we admire in animals are manifest qua animal qualities. Against functionalist and formalist accounts, I defend and develop an account of expressive-responsive movement as the primary perceptual sense of animals. I go on to suggest that the primacy of movement in aesthetic appreciation of animals is also the primary sense of animal 'wildness' and that a key part of the rewilding paradigm should be the development of such appreciation.
\end{abstract}

\section{Keywords}

Animal aesthetics; primacy of movement; perceptual sense; Merleau-Ponty; wildness; rewilding.

\section{INTRODUCTION}

My claim in this paper is that the primary perceptual sense of our encounters with animals is the sense of their movement through a lived environment and that the 'aesthetic side' of this perceptual sense is animal wildness. Wildness, together with its modifications and curtailments, is the primary aesthetic sense of animal movement. The multitude of aesthetic qualities that animals display are manifest in and through their primordial wild movement.

I make the case for the primacy of movement in animal aesthetics by deploying the idea of 'perceptual sense' as developed by phenomenologists, especially Merleau-Ponty (e.g. 2012: 314). Perceptual sense refers to the meaning of things as they unfold in perception, prior to conceptualisation and judgement. Perhaps surprisingly, phenomenological accounts have rarely looked in depth at the aesthetic aspects of 
animal encounters in the context of ecological aesthetics. ${ }^{1}$ Environmental aestheticians have drawn upon phenomenological insights before, perhaps most significantly in Arnold Berleant's aesthetics of engagement (Berleant, 1992), but without any detailed consideration of the aesthetic significance of wild animal encounters. Phenomenologists have developed important accounts of human-animal relations (Atterton et al, 2004; Oliver, 2010) and environmental philosophy (Brown and Toadvine, 2003; Bannon, 2016), some focussing on the work of Merleau-Ponty (Cataldi and Hamrick, 2007; Toadvine, 2009), but rarely bringing to the fore the crucial conjunction between these two sets of concerns that comes in our aesthetic appreciation of animals. Others have begun to show that non-Western traditions, sometimes including perspectives and methods quite close to those of phenomenologists, can feed into an ecological aesthetics that highlights animal encounters, such as the Li and Ryan's analysis of the Chinese aesthetic of Yijing that incorporates a crucial component of bio-empathy (Li and Ryan, 2017). Nevertheless, none of these accounts make the link between the primary perceptual sense of movement and aesthetic sense of wildness in our encounters with animals living in their natural environments.

The phenomenological aesthetics with which I approach animal encounters is 'ecological' in that it takes the relationships between living beings and their lived environments to be the opening of fields of meaning. ${ }^{2}$ On this view, aesthetic appreciation is not a special kind of sense-making or perception of special qualities of things, but an integral aspect of all perception. Thus, animal movement as perceptual sense and animal wildness as aesthetic quality are two sides of the same coin. Ecological sense-making can be more or less immersive and holistic, and it can also integrate ecological knowledge, as do two models of ecological aesthetics that Berleant has recently contrasted (Berleant, 2016). However, the claim that perceptual sense is 'ecological' here means above all that it remains open to the multitude of intersecting fields of meaning that living beings are continually opening up in the course of their lives. Our sense of the 'whole', and our conceptions of what it is that we are perceiving, thus remain open-ended and need to allow for the uncertain and unexpected. Ecological sense-making takes the notion of 'meaningful relations' ${ }^{3}$ as the basis for environmental thought and emphasises two important features of such meaningful relations that stem from appreciation of the fact that living creatures are always making and remaking meaningful relations with one another and their natural environments: i) meaningful relations are 'ecological' because they are complex, multifarious, overlapping, intersecting, the result of a multiplicity of sense-makings, including, but not at all confined to, those of human beings; ii) meaningful relations are 'ecological' because they elicit attempts of make sense of this whole multiplicity whilst appreciating its 'open-ended' temporality. The living beings making sense of one another and their environments are continual remaking that sense.

I begin by showing that recognising the primacy of movement in the perceptual sense of animality does not entail closing ourselves to the manifold ways in which we

\footnotetext{
${ }^{1}$ Important moves in this direction can be found in Luft, 2013 and Lewis, 2018.

${ }^{2}$ See Greaves and Read 2015 for a general approach to ecological values as the result of ecological sense-making.

${ }^{3}$ See Holland, 2012 for the development of this notion as a basis for environmental thought and Palmer, 2010 for a similar approach directed specifically towards animal ethics.
} 
aesthetically appreciate animals and the many qualities that they manifest. On the contrary, recognising the primacy of movement directs us towards the basic perceptual sense that keeps us open to aesthetic plurality (section 2). I go on to argue that other approaches to animal aesthetics, such as functionalism (section 3) and formalism (section 4), make sense of animal aesthetic qualities in ways that are derived from the basic perceptual sense of their movement. Finally, I develop the idea that the basis of aesthetic appreciation is the open expressive-responsive perceptual sense of animal movement and, furthermore, that this primary perceptual sense of animality is also the primordial sense of animal 'wildness'. I make some suggestions as to how this can help us to understand the central significance of animals in the environmental imagination of rewilding (section 5).

\section{AESTHETIC PLURALISM AND THE PRIMACY OF MOVEMENT}

One important initial concern about my claim that movement is the primary basis for the aesthetic appreciation of animals might be that recent work in environmental and animal aesthetics has tended to emphasise the plurality of aesthetic responses and values. The plurality of aesthetic responses can be understood both in terms of what one appreciates and how one appreciates it (the 'noema' and 'noesis' as Husserl called them), and the multiple ways in which those two poles affect and shape one another. Pluralist accounts include Emily Brady's (2003) 'integrated aesthetic', which emphasises the diversity of aesthetic qualities that we appreciate in nature together with the diversity of attitudes and faculties that are involved in appreciation, as well as Ronald Moore's (2008) 'syncretic' account of natural beauty, which emphasises the various personal and historical experiences that are drawn together in our appreciation of natural beauty. There is ongoing debate as to the tenability of pluralism in environmental aesthetics. Glenn Parsons has distinguished 'modest pluralism', which admits the appropriateness of 'science-based', formalist and emotive responses to nature, so long as they are grounded in the actual qualities of the natural world, from 'robust pluralism', which admits the appropriateness of a whole range of aesthetic experiences, including 'cases where natural things are viewed as things they are not' (Parsons, 2008: 72). Parsons himself argues that since the actuality of natural qualities is measured by the truth value of scientific claims, 'science-based' experiences will always be the measure of the appropriateness of aesthetics experience of nature. This argument also informs his treatment of animal aesthetics, as we will see below. I challenge the ontological assumption on which this argument is based by introducing the phenomenological notion of 'perceptual sense' as the ground of our sense of actuality and thus appropriateness of aesthetic experience.

Emily Brady (2016) has more recently defended a 'critical pluralism' that allows space for imaginative and even fictional appreciation of nature, whilst remaining critically sensitive to the 'actual qualities' of the natural world. My account of animal aesthetics can be understood as a contribution to such a critical pluralism, which addresses more directly the meaning of 'actuality' in the case of aesthetic experience of animals.

In animal aesthetics, those who defend beauty as a significant platform for ethical and political judgement tend to embrace pluralism when it comes to elaborating what animal beauty consists in. Ned Hettinger, for example, sets out to defend animal beauty as a reason for preservation without committing to any particular account of what such beauty consists in and embracing a plurality of accounts (Hettinger, 2010, fn. 20). 
Significantly for my argument, Hettinger nevertheless begins his defence of animal beauty with some qualifying terms: 'If natural beauty amounts to anything, it includes the beauty of animals, wild and free, on the move.' (115)

Regarding the plurality of what we aesthetically appreciate in animals, Marta Tafalla has helpfully suggested that we move beyond 'beautiful' and 'ugly' towards the whole spectrum of aesthetic responses animals evoke:

Precisely what aesthetic appreciation of animals teaches us is that beautiful and ugly are only two of the great diversity of aesthetic qualities we value in different species, and also in the different behavior exhibited by the same species, which can be judged as elegant, harmonious, joyful, playful, graceful, fierce, majestic, imposing, delicate, fragile, tender, colorful, monstrous, comic, mysterious, enigmatic, interesting, melancholic, disgusting, terrifying, sublime, and so on. Some of these qualities prompt different kinds of pleasure in us, like joy, serenity, vitality, amusement, surprise, and so on, and others provoke different kinds of displeasure in us, for example, sadness, fear, or disgust. This plurality of aesthetic qualities is the appropriate way to admire biodiversity, which is the very core of nature. (Tafalla, 2017)

Linking the plurality of aesthetic responses to biodiversity in this way is an interesting strategy. Nevertheless, this view has a tendency identify each object of appreciation as a species-being and to draw us away from the perceptual sense of wild movement that is at the core of our perception of animal nature. It cognitively separates species from one another and from their lived environments, which is precisely what Tafalla wants to avoid in her argument that zoos cannot afford us a serious aesthetic appreciation of animals.

Approaching the issue from another angle, Stephen Davies (2012) has offered a wideranging analysis of the plurality of ways that we appreciate animals and the diversity of our historically developed aesthetic practices. Davies also wants to broaden the notion of the 'aesthetic' to include encounters that would be considered non-aesthetic by 'Kantian aesthetic formalists' on the grounds that they are either 'too cognitively loaded' or alternatively 'too simple' (65-66). The result is that animals are not necessarily appreciated on their own terms or in terms of their 'interests and identity'. Davies distinguishes nine types of aesthetic response to non-human animals: Analogy to features liked in humans (potentially tracking 'fitness'; likeness to baby humans and mammals); likeness to us (as part of the 'constant project of reading the minds and characters of others'); reflection on non-human natures and appreciation of their adaptation to their ways of life; 'The animal's color, form or movement automatically triggers our sensory biases in a positive fashion.'; 'We resonate to animals' mutual displays, social interactions or environmental locatedness.'; environmental taste as indicators of environmental health, utility and disutility; rarity or unusualness (can enhance but not ground aesthetic appreciation); viewing animals as artworks, literally as God's artworks or imaginatively as pseudo-artworks; and finally, we abstract their appearances from their natural contexts in order to engage aesthetically with these as formal, expressive, or sensory arrays (79-80).

The breadth of this analysis is again helpful insofar as it begins to make clear the wide 
range of responses and concerns that have been gathered together in the long and complex history of human aesthetic practices and responses to wild animals, a history that is of course still underway. Nevertheless, the tendency is again to obscure the perceptual sense that allows such an array of responses to be gathered under the heading of aesthetic appreciation of animals. It is movement as openness to the creature's lived situation that provides the perceptual sense of animality, shaped and reshaped by the complex genealogies and concrete contexts of our animal encounters. Whilst Davies only mentions movement explicitly as the focus of some of the responses he analyses, my aim is not to narrow the category of 'the aesthetic' once more, so as the exclude some of this range of experiences as non-aesthetic. Rather, understanding the primacy of movement in animal aesthetics draws attention to the perceptual sense that runs through all such responses in one way or another.

To begin to do this Merleau-Ponty's descriptions help us to recover the perceptual sense in which the whole range of aesthetic responses unfolds. In the following passage from Phenomenology of Perception Merleau-Ponty nicely encapsulates the difference between the objects-with-properties ontology that he thinks distorts so much philosophising and what phenomenological analysis of experience reveals:

[T] he bird that crosses my garden is, in the very moment of the movement, merely a grayish power of flight and, in a general way, we shall see that things are primarily defined by their "behavior," and not by static "properties." It is not I who recognize, in each point and in each instant passed through, the same bird defined by explicit properties; rather, it is the bird in flight that accomplishes the unity of its movement, it is the bird that changes place, and it is this feathery commotion still here which is already over there, in a sort of ubiquity, like the comet and its tail. (Merleau-Ponty, 2012: 288)

Although the point is a general one, I do not think that it is an accident that a bird prompts this thought. Merleau-Ponty is drawing out the implications of a phenomenology of perception into an ontology that goes beyond the object-property ontology that obscures the primordial perception of the bird's flight. That ontology also moves beyond what has been called the 'Gestalt-ontology' of his early work in the Structure of Behavior (Toadvine, 2009: 21). In this passage we find the inklings of what might be termed a 'Gist-ontology', that finds the being of things in their primal and characteristic movements. ${ }^{4}$ Animality is the intense manifestation of movement in perceptual sense and it is in aesthetic appreciation of animal movement that we appreciate them for what they are in this primal sense.

My intention here is to demonstrate that the primacy of movement has a crucially aesthetic sense that can help us to address emerging debates concerning wild animals

\footnotetext{
${ }^{4}$ My term 'Gist-ontology' alludes to one possible etymology of the term 'jizz', designating the identifying 'basic character' of a bird in movement and comportment. The term has been taken up in other fields of biology and ecology. The origins of the term are unknown and highly contested. One interesting possibility in this context is that it is a corruption of 'Gestalt'. See McDonald, 1996 for an overview of the meaning and origin of the term.
} 
in environmental philosophy. ${ }^{5}$ I argue that animals appear so prominently and intensely in the natural world as we perceive it because their expressive-responsive movements draw our attention not first to the qualities and forms of their bodies, nor even to species-specific 'movement signatures', but to their unfolding relations to those around them and the open-ended environments they move through. Animals are self-moving, but never absolutely self-moving, and the aesthetic sense of their wildness is relational self-movement. Wild movement thus understood is not a quality amongst others that an animal either has or does not have, but the primary perceptual sense of animality itself. Wild movement is the perceptual sense that unfolds to us the whole spectrum of aesthetic qualities that we appreciate in animals.

\section{MOVEMENT, VITALITY AND PURPOSE}

To substantiate the claim that movement is primary to the aesthetic appreciation of animals it will be helpful to examine some prominent criticisms of this view. In this section I will look at the arguments put forward by Glenn Parsons (2007) against the primacy of movement and in favour his own 'functionalist' view. In the following section I will examine how formalism tries to deal with the aesthetic qualities of animals. In both cases movement is acknowledged as a significant aesthetic feature of animals, but it is thought to require grounding in a framework that understands movement as one aesthetic quality amongst others. In so doing these views miss both the specific phenomenal sense of animal movement as perceived wildness that I will go on to set out, but also fail to understand that it is actually this phenomenal sense that 'grounds' and structures appreciation of all animal aesthetic qualities.

In his survey of various possible approaches to animal aesthetics Parsons is quick to dismiss the movement approach. His argument rests in part on a decontextualised reading of Hegel's claim that animal animation and animal beauty are intrinsically linked. If we return Hegel's claims to their context they actually turn out to have certain affinities with Parsons's own 'functionalist' approach. Both Parsons and Hegel ultimately characterise animal movements as evaluable in terms of purposiveness, fitness or functionality, in a way that unduly restricts their phenomenological sense and aesthetic appreciation.

Parsons cites Hegel, alongside Ruskin, as examples of what he sees as an anthropomorphic moralising tendency (Parsons, 2007: 157). According to this view animals that display greater active vitality are judged to be more beautiful, and the extremely inactive judged ugly. This is epitomised in Hegel's infamous criticism of the sloth in the introduction to his lectures on Aesthetics:

[..] the sloth displeases because of its drowsy inactivity; it drags itself painfully along and its whole manner of life displays its incapacity for quick movement and activity. For activity and mobility are precisely what manifest the higher ideality of life. (Hegel, 1975: 130)

\footnotetext{
5 The idea of the 'primacy of movement' has previously been deployed, independently and in different contexts, by Maxine Sheets-Johnstone (2011) and Tim Ingold (2011). Whilst both accounts support what I have to say here about the primacy of movement in a general sense, neither focuses specifically on its implications for animal aesthetics.
} 
Without wishing to defend what does indeed seem to be a rather hasty negative judgement of the sloth, it is important to get clear about precisely what claim is being made and on what grounds. Earlier in the text Hegel has claimed that the perceptual basis of aesthetic appreciation of animals is their animation (124). Later, in the passage cited, he is concerned with the various aesthetic judgements that we make, considering why it is that some animals are judged more beautiful, and some less beautiful or ugly. The problem is that Parsons does not distinguish the claim of the primacy of movement, i.e., that movement is the perceptual basis of all aesthetic judgement of animals (positive or negative), from the claim that quick or vital movement is judged positively. An unconvincing assessment of how we ground positive or negative judgements in particular movements does not in itself invalidate the prior phenomenological claim that animation is the perceptual basis of aesthetic appreciation, and thus also any aesthetic judgement. Furthermore, it appears that Hegel himself when considering the positive judgement of quick and vital movement is concerned not simply with the quickness of the movement as such, but with the perceptual quality of that movement. The sloth is judged to be ugly not simply because it is slow, but because it appears to 'drag itself painfully along.' That suggests that a beautiful movement showing 'the higher ideality of life' would appear effortless, like the beauty of a ballet dancer as compared to a weightlifter. If that is the suggestion then numerous problems will still arise. If animal beauty is an effortful self-movement made to seem effortless, what should we make of the gliding of birds on thermals, that appear as an effortful avoidance of effort? Or a salmon run that is impressive precisely as manifesting the supreme effort of a fish versus river? Those are problems for the formation of positive and negative judgements if beauty is restricted to effortless vitality, but their solution will involve more precise phenomenological analysis. They are not problems for the claim that movement is the perceptual basis for any appreciation, which in turn may or may not be used to ground positive or negative judgements.

If we return Hegel's problematic judgement to its original context, ${ }^{6}$ his understanding of the importance of movement in animal aesthetics brings him closer to Parsons's own preferred 'functionalist' view than one might expect. The section of Hegel's text on 'Life in Nature as Beautiful' begins with the claim that the first thing to strike us about living beings in nature is their capricious movement. Closer inspection reveals living movement to involve an inner purposiveness (i.e. vital needs and desires) and a third look, or rather thought, begins to understand the system of nature that has brought about that inner purposiveness (Hegel 1975: 124).

\footnotetext{
${ }^{6}$ Recent work in Hegel scholarship has shed significant light on the opening sections of the Lectures on Aesthetics that deal with natural beauty, showing how they fit into Hegel's dialectic as a whole and their importance for animal aesthetics. Julia Peters (2015: 18-27) highlights the role of the concept of habit, as it is developed in Hegel's anthropology, for understanding his claims about the superior beauty of human over animal bodies. Michael Lewis (2018) focuses on the various grounds for judging animals to be ugly that Hegel avers and situates these in relation to the key notion of the 'bad infinite' that informs Hegel's thinking of nature. Both of these scholars make clear the importance of unity, subjectivity and autonomy as informing Hegel's aesthetic ideal, which can be contrasted with the aesthetic ground of wild 'perceptual sense' that I am advocating here.
} 
It is these second and third takes on living movement that bring Hegel very close to the 'functionalist' view. When vital needs and desires are explained in terms of their function in the 'system of nature' they are understood as emergent functions within that system. Parsons thinks that the evolutionary concept of 'fitness' can ground perceived purposiveness. A tension between fitness as an explanatory concept and manifest functionality then arises in Parsons's own key example of animal beauty arising from perceived 'fitness':

Take the cheetah, a creature whose body, like that of the racehorse, appears "built for speed." Virtually every feature or part of the cheetah is manifestly geared to that end: its long legs bespeak a formidable stride, its nonretractable claws reveal its gripping and steering ability, its narrow body and small head bespeak an aerodynamic movement, and so forth. This manifest fitness gives the cheetah's appearance a certain pleasing visual quality: it "looks fit." A similar account could be given for the appearance of many animal features, from the broad wingspan of a gliding raptor to the dexterous lankiness of a tree frog's toes.

(Parsons, 2007: 162)

Any manifest functionality on this list of bodily features has as its assumed background the famed speed of the cheetah in the chase, which many people have witnessed on TV and film footage, even if they have not seen it first hand. However, all of the features listed here could well be noted in a photograph, drawing or taxidermy specimen. It is only insofar as footage, photograph, drawing or specimen are able to give a sense of the lived movement of a hunting cheetah that the functionality becomes manifest in any of these cases, otherwise the features can be noted and explained as functional elements, but are not perceptually manifest as such. The assumed background to which each feature points is the manifest movement of a cheetah as it gingerly stalks through the high grass; as it begins to lope towards its chosen prey still assessing whether to abort; as it reaches its full stretch and must then turn vertiginously as its prey turns. The lived movement is what is aesthetically appreciated, moving from subtle shifts, to awkward wariness, to utterly absorbed speed. The understanding of the bodily features that make it possible is aesthetic appreciation of the animal only insofar is it points us back to that assumed background.

We must question whether the manifest lived movement that is aesthetically appreciated is best described in terms of 'fitness.' As Parsons implies, there is a clear purposiveness in the chase that manifests the 'inner purposiveness' of need and desire. If 'fitness' is the ability to successfully fulfil purpose, then one might wonder whether there is more to be appreciated in a chase that results in a successful kill. That seems unlikely, as does the correlative thought that aesthetic appreciation shifts from the cheetah's movement to the prey's movement if the hunt fails. The fact that the majority of chases in wildlife documentaries result in a kill need not lead us to think that there is more to be aesthetically appreciated here, but perhaps only that prejudices in favour of a certain idea of the chase coming to fulfilment overlay its primary perceptual sense, prejudices that may need to be overcome. ${ }^{7}$

7 The BBC's 2015 documentary The Hunt explicitly sets out to correct this usual emphasis on the kill: 'the kill itself isn't interesting, because once animals have killed, 
The move to 'adaptive' fitness brings out the tension between Parsons's idea of 'looking fit' and the evolutionary-ecological concept of fitness. It is quite possible for the cheetah to 'look fit' in the sense of manifesting purposive speed and precisely for that reason to be ecologically 'unfit' because its speed adaptations mean that it occupies a narrow niche that may be closed off, e.g. its range of possible prey is narrow. Fitness in the sense of ecological and evolutionary science is a statistical function of a population-in-environment and is often divorced from 'looking fit,' both because of the prejudices such a look can harbour and because of the unexpected vicissitudes an environment can throw at a population. ${ }^{8}$

Whether all animal movement has such manifest purposiveness is also questionable. We can attempt to explain play of all kinds as adaptive, but whether or not those attempts are convincing, the very open-ended expressive-responsive movements of play do not primarily manifest as functionality. Yet they are prime occasions for aesthetic appreciation, both on our part and often on the part of the animals themselves.

The primary perceptual and aesthetic sense of animal movement is neither pure capriciousness nor determinate understanding of the system of nature. Perception of animal movement begins with the middle term, as Merleau-Ponty might say, from which senseless capricious movement and explanatory understanding are both abstractions. For an ecologically aesthetic appreciation of animals, 'inner purposiveness' must be broadened to an appreciation of the interactive movements of animals amongst others and moving through their environments.

For Hegel, the system of nature produces higher and higher manifestations of a concrete activity that begins in 'inanimate' nature:

In a still higher, more concrete, way a similar activity of immanent formation [to the formation of crystals] is displayed in the living organism, and its outline, shape of limbs, and above all its movement and expression of feelings. (Hegel, 1975: 130)

the story's over. What is interesting is the build up, the strategies adopted by both the predators and prey.'

http://www.bbc.co.uk/programmes/articles/57m0bYByVs3JFCw1XJbWgGy/introduc tion-to-the-hunt (accessed 1 Sept 2017)

${ }^{8}$ Parsons and Allen Carlson return to the cheetah example in their jointly authored book Functional Beauty (2008). There they explain that 'looking fit' in the sense they intend can involve knowledge of function or fitness becoming part of perception. This is certainly a point that I would concede, following Merleau-Ponty's thought that intellectual understanding can become 'sedimented' in perceptual sense. However, the tension that I highlight between fitness as explanatory concept and fitness as manifest function is still present. Furthermore, they add that "looking fit" is not the only form of Functional Beauty applicable to animals' and that natural selection often shapes traits to have functions that do not 'look fit' (120, fn 23), highlighting the fact that scientific understanding of fitness can still diverge from perception at crucial points. 
This formulation takes us to the next attempt to incorporate the perceptual sense of animal movement into a purportedly broader framework that I address in the following section, that is, formalism that takes movement to be one set of formal qualities that animals possess, along with outline and shape of limbs, amongst others. I then take up Emily Brady's suggestion that we appreciate animals for their expressive qualities, and develop my own claim that such expression is not one set of qualities amongst others but integral to the concrete phenomenal sense of expressive-responsive movement, which in turn is the primary source of aesthetic qualities qua animal qualities. This perceptual sense of animality, I will argue, is ultimately also the primordial sense of animal 'wildness.'

\section{MOVEMENT, FORM AND STILLNESS}

Formalist approaches to animal aesthetics treat movement as one set of formal qualities amongst others and question the need to privilege one set of such qualities. My response to this kind of approach is that it is only under certain conditions that abstract from their original perceptual and aesthetic sense that animal movements can be so regarded. As originally perceived it is in and through animal movement that aesthetic qualities are manifest and only then can they be formally analysed. I will distinguish two elements of the process of abstraction: the abstraction of forms and the abstraction of sense.

The abstraction of forms is what allows formalists to identify different 'formal qualities' and to consider them as separate, or at least ideally separable. Stephen Davies, as we saw in section 2, lists as formal qualities 'colour', 'shape' and 'movement', noting such formalism is only one kind of appreciation that requires abstraction from the lived perception of animals in their environments. We can see that this approach relies on abstraction through separation. Contrast this to Merleau-Ponty's description of the bird as a 'greyish power of flight'. The greyishness is not amalgamated with the power of flight, but is a quality manifest in the power of flight. In the animal world outlines, shapes, colours and calls are not simply set before us in various combinations, they are manifest in display, ritual, chase, escape, and all manner of movement. The flash of white under the wing of a greyish power of flight is not a formal property only now revealed, but a further unfolding of that very movement.

The abstraction of forms need not be the result of explicit processing of experience. Even the descriptions of Gestalt psychologists and others who focus on situated perception can betray formalisation. In an analysis of what he describes as J.J.Gibson's 'ecological phenomenology' Claude Romano recalls Gibson's critique of the tendency in Gestalt psychology to consider dynamic structures of perception as conforming to formal structures. For Gibson, Romano argues, 'perception is not first perception of invariable forms, but of informal invariants' (Romano, 2016: 164). Such invariants arise in the dynamic and originally formless movements through which animals respond to the affordances of their environments. As I conceive of it, ecological aesthetic appreciation of animals in their lived environments involves the perception of their dynamic movements and the informal invariants that are manifest in them. Take the mating display of Great Crested Grebes, during which each stands up in the water and presents weed to its partner shaking its head. This movement greatly increases its 'height' above the water as its stands, whilst its bill becomes an invariant of length extending towards its partner now that the presentation cannot be made with the 
extension of the neck. In other movements of the display the bill and neck, and even the whole length of the body, are extended toward the other and are thus not seen as separate lengths. The movements of the two birds together are dynamic expressiveresponses to one another and their environment. This is not a complex amalgam, but an experience all at once of the animals' lived movement as a dynamic exchange of variant and invariant, not only in bodily lengths, but expression and response in relation to one another, the weed and the water. The dynamic invariants in the case of perception of animal movement are manifest in the course of the movement that opens the environment to the birds, and in my appreciation of their movement it also reveals that environment to me. The abstraction of form separates invariants from the movements in which they become manifest, but also begins the process of closing down the overall perceptual sense of movement through an environment.

That further process, which I call the 'abstraction of sense,' is intimately related to the first. Formal qualities are more easily separated if their overall sense is extracted from their lived context and the open character of animal movement is curtailed. A prominent exponent of formalism, Nick Zangwill, goes so far as to claim that the surprisingly dainty formal quality of a polar bear's swimming that he sees from underneath in a tank at the zoo would not be affected if it transpired that this were in fact a man in a polar bear suit (Zangwill, 2001: 214). Glenn Parsons dismisses this peculiar judgement with the same haste that he dismisses Hegel's judgement of the ugliness of the sloth (Parsons, 2007: 160). A phenomenological analysis of the apparent grounds for such an unlikely claim can be more revealing and shed light on what occurs in formalist abstractions. Perhaps the bear's swimming is thought 'surprisingly' dainty in mental comparison with its lumbering gait on land, recalled from another zoo enclosure or television images. The sense of this experience is thus revealed as a collaged amalgam of contrasting snippets of movement. It would be quite different, I think, if one were able to lumber along with the bear and then plunge into the water and swim alongside it. Or even to observe it from a kayak as it lolloped towards a break in the ice and then took the plunge. The contrast between run and swim might still be there, but as a modulation of a continuous movement with its own sense as the bear moves from ice to water. It is only the situation of delimited movement, inviting a collaging of sense, that makes the formalist claim regarding the man in the suit scenario even vaguely plausible. Of course, such situations are not at all uncommon, and they may well even be the majority of situations in which animal movement is now encountered. But that frequency does not allow the formal abstraction of sense to overcome the primacy of real embodied movement through an environment, upon which it still depends for whatever abstracted sense it possesses. We should take careful note of the fact that the 'abstractions' that allow for formalist separation of qualities and curtailing of overall perceptual sense are not simply 'armchair' cognitive or imaginative operations. They involve the cultivation of specific perceptual habits in particular kinds of media representation and also the actual extraction of animals from their lived environments, as in the case of this polar bear. ${ }^{9}$

In sum, my claim against formalism rests on a phenomenological analysis of form as the result of specific perceptual habits and practices that curtail or contain the open

9 These considerations should add further weight to Marta Tafalla's powerful arguments against the possibility of serious aesthetic appreciation of animals in zoos (Tafalla 2017). 
unfolding of the perceptual sense of animal movements. I agree to a certain extent with general anti-formalist arguments, such as those proposed by Parsons and Carlson, that hinge on the claim that engagement is the appropriate way to appreciate nature aesthetically and that 'framing' produces forms that involve artificial imposition (e.g. Parsons and Carlson, 2004). The difference is that a focus on the perceptual sense of movement reveals it as primarily open-ended, incomplete, lived or 'wild' sense-making in which the animal expressively responds to its environment, and it is perceptual engagement with that primary sense of movement that reveals that animal and its world to me for appreciation. It is in cultivating awareness of the perceptual sense of their movements that we aesthetically appreciate animals. Formalist abstractions ultimately also rely on awareness of this sense, even as it is contained and curtailed, since 'framing' is not necessarily entirely arbitrary. I do not, for example, draw an imaginary vertical line down the centre of the polar bear's body as it swims and try to perceive the left and right limbs as working independently from one another. The attempt would surely be only of very limited success, and insofar as it succeeded, the 'daintiness' that so impressed Zangwill would be obliterated.

One might object at this stage that form is what we appreciate in animals that are still, and the fact that stillness does not prevent aesthetic appreciation tells against the whole idea of the primacy of movement. My response to such claims is that stillness and movement are not separable moments of animal lives. We will see in the next section that anticipation or the 'imminence' of movement is crucial to its wild perceptual sense.

Stillness isn't simply the shadow of actual movement, but rather it is an integral anticipation of movement itself, and vice versa. Stillness and movement are not perceived and aesthetically appreciated as potential and actuality, as some of have argued in response to this concern (e.g. Rolston III, 1987: 188). Martin Heidegger makes this point in his close reading of Aristotle's Metaphysics $B$ by distinguishing movement from what he calls 'movedness' as the principle of nature. Movement and stillness together manifest fundamental 'movedness': 'The purest manifestation of the essence of movedness is to be found where rest does not mean the breaking off and cessation of movement, but rather where movedness is gathered up into standing still, and where this ingathering, far from excluding movedness, includes and for the first time discloses it.' (Heidegger, 1998: 217). The movement of wild animals preeminently manifests the integration of movement and 'standing still'. To take up an example that Heidegger suggests without drawing out this particular implication, a bird of prey circling above the forest is moving and still within itself (212). The perceptual sense of each movement includes the stillness from which it unfolds and returns to stillness, and the sense of stillness includes the movement that is gathered up into it, which it has arrived from and where it can go from here. Each movement is an actual manifestation that at the same time has gathered within it immanent stillness, not as mere possibilities of what might happen next, but as the sense of what is unfolding. The aesthetic appreciation of animal movements is also, in each case, an appreciation of the lived environment that animals move through and stand within. The resting moth rests differently on a garden wall in the evening to one on the bedroom wall after a night hurling itself at the lightbulb. The poised spider with several wrapped flies in its web has a different poise to one with nothing but fresh dew festooning its trap. The stick insect that stands still for all the time I observe it, stands in a stillness with a field of movements gathered into it, quite different to the sticks that surround it once I am able 
to see it as such.

\section{WILDNESS AS EXPRESSIVE-RESPONSIVE ANIMAL MOVEMENT}

I now want to develop the idea that 'wildness' in this context should not be understood as one possible feature of animals amongst others, but essentially linked to the open movements that are primary to perceptual and aesthetic appreciation of animals as such. Animal wildness is the open expressive-responsiveness of animal movements through their lived environments.

Certainly, there are many senses in which animals are said to be wild, senses which can interweave and even pull against one another in complex ways. Clare Palmer, for example, has analysed three senses of animal 'wildness' (2010: 64). 'Constitutive wildness' contrasts the wild with the domesticated, often, but not always, focussing on the intentional influence that human activity has on the genetic structure of animals. 'Locational wildness' contrasts the wild with the urban, designating animals as more or less wild according the degree of wildness assigned to their location. 'Behavioural wildness' contrasts with tameness, tending to focus on aggression or fear towards humans as characteristically 'wild' behaviours. Palmer emphasises that each of these senses of wildness forms a spectrum rather than dichotomy, and that they do not always map onto one another neatly.

The sense of wildness that I have in mind is not any one of these specific categories. Each of Palmer's spectra ranges primarily over the properties or characteristics discerned in individual animals viewed as specific intentional objects. Instead, when I refer to 'wildness' here I have in mind what Merleau-Ponty refers to in notes towards his last work The Visible and the Invisible as 'wild being' (1968: esp.167-170). Wildness in this sense is the correlate of the primary layer of perceptual sense that I have highlighted. It is wildness of both perception and perceived, intimated in the openended multi-dimensional dynamics of the perceptual world. It is my contention, although I am unable to fully substantiate this claim here, that all the categories of wildness draw their sense from primordial wild being that Merleau-Ponty equates with the perceived world (170). To give an indication of what I mean: constitutive wildness refers not simply to the lack of intentional human influence on the constitution of an animal, but the concomitant open expression and responsiveness of the animal's embodied motility that has not been made to 'fit' with human desires and expectations. Behavioural wildness, even in cases where it is bred into an animal, similarly refers back to open-ended uncertainly of fit between human and animal as each make sense of the world they find themselves in. Locational wildness refers to the relatively intense multi-dimensionality and uncertainty, from one's own current perspective, of ecological sense-making in some locations relative to others. None of these categories is precise or absolute, precisely because they gain their sense by referring back to the open-ended and uncertain perceptual sense of wild being.

As Merleau-Ponty understands it 'wild being' is not eradicated or replaced by categories that aim to give us a completed and thus 'tamed' vision of the world, a vision that goes along with the idea that the perceptual world is the result of discrete 'acts' of human consciousness. Rather, wild being remains the latent, embodied and mobile, ground of sense, the 'imperception' in perception, that remains ignorant of itself in categorisation and the analysis of perception into discrete intentional acts (213). 
Understood in this way, we can see why animals play such a key role both in MerleauPonty's elaboration of the wild being of the perceptual world and in the contemporary aesthetic imagination of rewilding. Thinking of animal wildness in this way avoids an idealised notion of complete absence of all human encounter, as well as the idea that wildness is a single quality or property that each animal either possesses or lacks. Wildness as open and uncertain temporality is manifest preeminently in the open expressive-responsive movements of animals through their environments. As such it is not a quality simply present or lacking, but the very being of animals as relative intensity of the dynamic movement of wild being, through which animal qualities, amongst all natural qualities, become manifest.

The notion of wildness has received renewed attention in recent debates due to the emergence of 'rewilding' as a new paradigm in ecological restoration. The rewilding paradigm shifts the temporality of 'restoration' away from an imagined pristine past towards an imagined future in which nature is set (at least relatively) free from strict managerial regimes to manifest itself in potentially unexpected and even unimagined ways (Prior and Brady, 2017). It paradoxically rests on the imagining of an open, unseen or unimagined future, adding a temporal dimension to the paradox of wildness identified by Martin Drenthen (2005) as the spaces outside of culture that are continually appropriated as such back into culture.

Uncertainty and the unexpected are central to the notion of wildness. Furthermore, the 'reintroduction' of wild animals, often apex predators or other 'charismatic megafauna' looms large on the rewilding agenda. Prior and Brady (2017) therefore suggest that the aesthetic result is likely to be further encounters with 'terrible beauty' in the form of predation, and other potentially uncomfortable aesthetic experiences, such as encounters with disease. I think that there are even closer connections between the sense of wildness and animal encounters, that suggest why 'releasing' animals into the wild and allowing them to return of their own accord is such a central part of the rewilding agenda. That is because the perceptual sense of an open and uncertain future is generated most intensely and directly in animal encounters, when we follow along with their expressive-responsive movements through their lived environments. Rewilding should therefore be understood as in large part an aesthetic project in which specific practices of ecological restoration work alongside a 'rewilding of experience' in which we cultivate appreciation of wildness, especially manifest as the multitude of expressive-responsive animal movements.

The analysis of the primacy of movement in animal aesthetics that I have provided can help us to understand how various aspects of this notion of wildness fit together, and why wild animals loom so large in the environmental imagination of rewilding.

Emily Brady (2014) has herself provided some further clues in the course of an argument that expressivism has been a neglected alternative in animal aesthetics. One might at first think that the significance of animal emotional expression is an alternative approach to my own, but that would be a mistake, as Brady's own examples tend to show. Brady helpfully points out the limits of 'resemblance theories' that try to account for the appreciation of animal expression through their resemblance to familiar and typically human expressive behaviour. She also makes important links between appreciation of expressive behaviour and the symbolic characterisation of animals. 
When it comes to 'literal expression' she suggests that such expressions are the outward expression of 'mental states' and have generally been neglected by aestheticians and left to psychology and behavioural studies. Taking up an example from R.G. Collingwood that was also used by Parsons to exclude 'sympathetic response' from aesthetic appreciation, she argues that the bright eyes of animals are genuine occasions for aesthetic appreciation:

We can and do make aesthetic judgements which distinguish between dull, insipid or tired eyes and, say, the poise and narrowed eyes of a wild cat about to pounce. We may find the appearance of those eyes interesting for their expression of vitality and expectant look- and perhaps also for the thrilling pounce that we expect to follow from that look. (197)

The significance of this example is that it recontextualises the appreciation of bright eyes in an encounter with an animal living in its environment through the expressiveresponsive movement of its whole being. The bright eyes are not admired as isolated jewel-like objects, but manifest their specific brightness as an intrinsic part of the poise, the 'ingathering', of the cat about to pounce. The bright eyes may indicate health, as Brady goes on to note, but there again the aesthetic appreciation of such an indication comes in this context of wild, expressive-responsive, movement, not as one item on a checklist of health indicators in a veterinary examination.

Expectation plays a key role in the appreciation of this wild movement, which can seem paradoxical if we conceive of wildness in terms of the uncertain and unexpected. In fact, expectation and the unexpected are intrinsically bound together in these experiences. There can be nothing unexpected if the movement itself does not inculcate expectations which may then be fulfilled, confounded, or more or less subtly modified. In his lectures on Nature Merleau-Ponty calls this expectation that he earlier described in the movement of the 'greyish power of flight' the 'imminence' of perceived movement: 'This is not only an already made trajectory, nor even a trajectory that will be, but a trajectory that is going to follow. It is the grasp of the imminence of what is going to follow in what has already begun.' $(2003,154)$. This is the imminence of the wild cat's pounce in its poise with narrowed bright eyes. At the same time, the imminence of what is going to follow can take quite unexpected turns as it is followed through. Unexpected both for the moving animal and for those following along with it. The animal expresses itself and responds to others as it does so. Perhaps it catches wind of me watching just as it is about to pounce and flees. Wildness involves the generation of open expectations and uncertain indeterminate imminence.

It is for this reason that I insist that expressive movement is always at the same time responsive. Furthermore, the idea of animal expression needs to leave room for the indeterminacy and openness of wild movements that are expressive. Rather than the representationalist notion that expressions are outward manifestations of inner 'statesof-mind,' with the concomitant thought that those minds are already made up before they express themselves, it would be better to understand expressive-responsive movement as the embodied movement of those minds themselves. Following MerleauPonty and others, some thinkers of the embodied mind have suggested that 'expressive movement' rather than representational capacity is primary to mindedness (Levin, 2016; Sheets-Johnstone 2011). Collingwood's own thinking of the 'aesthetic' as artistic 
activity that expresses emotion, actually leaves some leeway for thinking in these terms, since he insists that expression is not the outward manifestation of already constituted states of mind, but itself the creative and imaginative manifestation of individual emotions from inchoate feelings (Collingwood, 1958: 109). Whilst he does not consider what this might mean for our appreciation of animals, having excluded our sympathy with life from artistic activity, other thinkers such as Deleuze and Guattari insist that animal movement becomes expressive in various ways, such as territorial markers and courtship displays, and that 'from this standpoint art is not the privilege of human beings.' (2004: 349). Whether or not one is happy to call animal expressions art, it should be clear that the expressivity of animal movement can be fruitfully seen as related to artistic activity and also that the appreciation of it feeds into human artistic activity, as Brady (2014: 199) also notes.

If the wild being of animals is open and indeterminate movement this is because of and not despite the imminence of movement. The unexpected is a twist on the expected, not the entirely capricious or chaotic. We can then begin to see why the temporality of the future is so important for the rewilding imagination and also why wild animals feature so prominently there. The long-term 'deep time' future that Prior and Brady point to is in fact an imaginative practice that opens a space for what is not yet perceived or even imagined. Allowing natural growth and movement to gradually 'take over' is to rewild our own imaginative capacities. But the uncertainty of the imagined 'deep' future is only one uncertainty of the rewilding imagination and we should also appreciate the 'micro' uncertainties of perception. Wild animals feature prominently here because it is in their expressive-responsive movements that we actually perceive wildness as imminence with a leeway for the unexpected. As we have seen, predation in particular features prominently in the appreciation of wild animal movement, from the cheetah's run to the pounce of the wild cat. This is not primarily, I would suggest, because of the excitement of possible danger, or what Hettinger (2010: 133) describes as an ambiguous feeling of 'terrible beauty' related to the aesthetic appreciation of the tragic, although those feelings may play a certain role. Rather, predation is above all a perceptual distillation of the open experience of wildness. There are always at least two involved in the movement of predation, and often many more. Their expressiveresponsive movements correspond and intertwine with one another, opening a wide and complexly structured field of imminence. The excitement is not compressed into an expectation of a kill, or the functionality of kill or escape. It is the whole uncertain and open movement of watching, stalking, ambushing, chasing that make predation a distillation of animal wild being.

\section{CONCLUSION}

I have argued that phenomenological description and analysis can contribute to debates in animal aesthetics, just as it has done in animal ethics and environmental philosophy more generally. My aim has been to show that the concern that aesthetic practices should seek to appreciate animals for what they are (Parsons, 2007) can be met if we take this to mean that we must focus on the primary 'perceptual sense' of animals, that is, their wild movement as the dynamic that makes their aesthetic qualities manifest. This original animate movement is both expressive and responsive, and thus open and indeterminate. The aesthetic side of that primary perceptual sense of open movement is animal wildness. Animal wildness is appreciated in and through aesthetic practices that cultivate the perceptual sense of their movement. Ultimately, wild movement is not one 
perceptual and aesthetic quality amongst others, but the basic perceptual sense through which the multitude of animals' aesthetic qualities become manifest.

Appreciation of the primacy of wild movement for aesthetic appreciation of animals leaves a number of paths open for further exploration. In the context of environmental aesthetics and philosophy, one of the most significant of these will be to describe and understand the 'wildness' of other elements of the natural world. The movement of the elements, including wind and water, and even earth and rock (e.g. as lava or shifting sands) has a quite different phenomenological and aesthetic character from the expressive-responsive movement of animals. The growth of plants, together with their generally unperceived movements, has another such character. Plants have begun to feature more prominently in philosophical discussion (Hall, 2011; Marder, 2013; Maher, 2017), yet this is often with a view to attributing 'perception', 'mind' or even 'personhood' to them, whilst their specific aesthetic character, especially as manifest in lived environments intertwined with animals and the elements, has yet to be thoroughly examined.

A second path for further inquiry would be to develop the suggestion I have made here that aesthetic appreciation of wild animal movement is part and parcel of artistic practices that both allow animal movements to follow through in their uncertain perceptual sense and cultivate attention to their unfolding imminence. In this sense, rewilding should be seen in no small part as just such a practice, or perhaps better, as a whole emerging tradition of such practices. More or less familiar artistic practices, such as photography, film-making and sound recording, together with newer and emerging forms of aesthetic practice that allow us to follow animals' wild movements, can and should form important parts of that emerging tradition. Rewilding as an emerging artistic and aesthetic tradition could then be understood in contrast to all of those aesthetic practices, often using the same media, that have sought to capture and curtail the wild movement of animals in innumerable ways, and to which rewilding is at once an aesthetic and ethical response.

\section{ACKNOWLEDGEMENTS}

I would like to thank Catherine Rowett, Rupert Read, Samantha Earle, Silvia Panizza, Simon James, audience members of the Warwick University Post-kantian philosophy seminar and two anonymous referees for helpful comments on this paper. 


\section{REFERENCES}

Atterton, P and M. Calarco. 2004. Animal Philosophy: Ethics and Identity. London and New York: Continuum.

Bannon. B. E. (ed.) 2016. Nature and Experience: Phenomenology and the Environment. London and New York: Rowman and Littlefield International.

Berleant, A. 1992. The Aesthetics of Environment. Philadelphia: Temple University Press.

Berleant, A. 2016. 'Some Questions for Ecological Aesthetics'. Environmental Philosophy 13 (1): 123-135.

Brady, E. 2003. Aesthetics of the Natural Environment. Edinburgh: Edinburgh University Press.

Brady, E. 2014. 'Aesthetic Value and Wild Animals' In M. Drenthen and J. Keulartz (eds), Environmental Aesthetics: Crossing Divides and Breaking Ground. New York: Fordham University Press.

Brady, E. 2016. 'Aesthetic Value, Nature and Environment'. In Oxford Handbook of Environmental Ethics. Stephen M. Gardiner and Allen Thompson (eds.). Oxford: Oxford University Press.

Brown, C. S. and T. Toadvine (eds.). 2003. Eco-Phenomenology: Back to the Earth Itself. New York, State University of New York Press.

Cataldi, S.L. and W.S.Hamrick (eds.) 2007. Merleau-Ponty and Environmental Philosophy: Dwelling on the Landscapes of Thought. New York: State University of New York Press.

Collingwood, R. 1958. The Principles of Art. Oxford: Oxford University Press.

Davies, S. 2012. The Artful Species. Oxford: Oxford University Press.

Drenthen, M. 2005. 'Wildness as a critical border concept: Nietzsche and the debate on wilderness restoration'. Environmental Values 14: 317-337

Deleuze, G. and F. Guattari. 2004. A Thousand Plateaus. Trans. Brian Massumi. London and New York: Continuum.

Greaves, T. and R. Read. 2015. 'Where Value Resides: Making Ecological Value Possible'. Environmental Ethics. 37 (Fall): 321-340

Hall, M. 2011. Plants as Persons: A Philosophical Botany. New York: State University of New York Press.

Hegel, G. W. F. 1975. Hegel's Aesthetics: Lectures on Fine Art. Trans. T. M. Knox. Oxford: Clarendon. 
Heidegger, M. 1998. 'The Essence and Concept of Phusis' In Pathmarks. William McNeill (ed.). Cambridge: Cambridge University Press.

Hettinger, N. 2010. 'Animal Beauty, Ethics, and Environmental Preservation'. Environmental Ethics 32 (2): 115-134

Holland, A. 2012. 'The Value Space in Meaningful Relations'. In HumanEnvironment Relations: Transformative Values in Theory and Practice. E. Brady and P.Phemister (eds.). Dordrecht: Springer: 3-15

Ingold, T. 2011. Being Alive: Essays on Movement, Knowledge and Description. London and New York: Routledge.

Levin, K. 2016. 'Aesthetic Movements of Embodied Minds: Between Merleau-Ponty and Deleuze'. Continental Philosophy Review 49 (2): 181-202.

Lewis, M. Forthcoming 2018. The Beautiful Animal: Sincerity, Charm and the Fossilised Dialectic. London and New York: Rowman and Littlefield International.

Luft, E. 2013. 'Bullough, Pepper, Merleau-Ponty, and the Phenomenology of Perceiving Animals'. Evental Aesthetics 2 (2): 112-123

Li, Q. and J. Ryan. 2017. 'Nature, Engagement, Empathy: Yijing as a Chinese Ecological Aesthetics'. Environmental Values 26 (3): 346-364.

Oliver, K. 2010. 'Animal Ethics: Towards an Ethics of Responsiveness'. Research in Phenmenology 40: 267-280

Maher, C. 2017. Plant Minds: A Philosophial Defense. New York and London: Routledge.

Marder, M. 2013. Plant-Thinking: A Philosophy of Vegetal Life. New York: Columbia University Press.

McDonald, D. 'The Etymology of "Jizz"'. In Canberra Bird Notes, 21 (1): 2-11 http://canberrabirds.org.au/wpcontent/uploads/2012/06/CBN/cbnvol21no1.pdf (accessed 17 February 2018)

Merleau-Ponty, M. 1968. The Visible and Invisible. Trans. Alphonso Lingis. Evanston: Northwestern University Press.

Merleau-Ponty, M. 2003. Nature: Course Notes from the Collège de France. Trans. Robert Vallier. Evanston, Illinois: Northwestern University Press.

Merleau-Ponty, M. 2012. Phenomenology of Perception. Trans . Donald A. Landes. London and New York: Routledge.

Moore, R. 2008. Natural Beauty: A Theory of Aesthetics Beyond the Arts. 
Peterborough: Broadview Press.

Palmer, C. 2010. Animal Ethics in Context. New York: Columbia University Press.

Parsons. G. and A. Carlson. 2004 'New Formalism and the Aesthetic Appreiation of Nature'. The Journal of Aesthetics and Art Criticism 62 (4): 363-376

Parsons. G. 2007. 'The Aesthetic Value of Animals'. Environmental Ethics 29 (2): $151-69$.

Parsons. G. 2008. Aesthetics and Nature. London and New York: Continuum.

Parsons. G. and A. Carlson. 2008. Functional Beauty. Oxford: Oxford University Press.

Peters, J. 2015. Hegel on Beauty. New York: Routledge.

Prior, J. and E. Brady. 2017 'Environmental Aesthetics and Rewilding' Environmental Values 26 (1): 31-51

Rolston III. H. 1987. 'Beauty and the Beast: Aesthetic Experience of Wildlife'. In Valuing Wildlife: Economic and Social Perspectives. Boulder and London: Westview Press.

Romano, C. 2016. There Is: The Event and the Finitude of Appearing. Trans. Michael B. Smith. New York: Fordham University Press.

Sheets-Johnstone, M. 2011. The Primacy of Movment (second expanded ed.). Amsterdam and Philidelphia: John Benjamins.

Tafalla, M. 2017. 'The Aesthetic Appreciation of Animals in Zoological Parks'. Contemporary Aesthetics 15, http://www.contempaesthetics.org/newvolume/pages/article.php?articleID=79 $\underline{3}$ (accessed 28 August 2017)

Toadvine, T. 2009. Merleau-Ponty's Philosophy of Nature. Evanston, Illinois: Northwestern University Press.

Zangwill, Nick. 2001. 'Natural Beauty' Proceedings of the Aristotelian Society 101: 209-24. 